\title{
The Importance of Occupational Medicine Outpatient Clinics; a Single Center Experience in Turkey
}

Mehmet Erdem Alagüney, [MD] ORCID: 0000-0001-7380-0250
'Konya Training and Research Hospital

The preliminary data of this article was accepted as an oral presentation in the 2 nd International Occupational and Environmental Diseases Congress, Antalya, Turkey in 2018.

Corresponding Author: Mehmet Erdem Alagüney Konya Training and Research Hospital

E-mail: alaguney@gmail.com

https://doi.org/10.32552/2021.ActaMedica.494

\section{w ABSTRACT Con}

Objective: The specialty of occupational medicine is newly developing in Turkey and the number of specialists and the specialty clinics are very few. The aim of this study is to present the first two-year data of an occupational medicine outpatient clinic. This clinic is unique as it is the first outpatient clinic in a secondary health care center in Turkey (except dedicated occupational disease hospitals), and the first residencytrained occupational medicine specialist in Turkey was running this clinic. The data will be compared with national numbers in order to show if these clinics make a difference in diagnosis and notification of occupational diseases.

Materials and Methods: The data is collected from the hospital database between 2017 August to 2019 August who applied to Occupational Diseases Clinic in the hospital. Only the patients who were referred by a physician or applied themselves with suspicion of an occupational disease are included to the study. The patients who applied for periodic examinations, fitness for work evaluations are not included.

Results: A total of 491 patients were included to the study. 444 of them did not have a prior diagnosis of occupational disease. Of these patients, 162 (36.4\%) were diagnosed with an occupational disease. $42.6 \%$ of these diagnoses were pneumoconiosis.

Conclusion: Occupational diseases are underdiagnosed and/or underreported in Turkey. A single center dedicated to occupational diseases made a substantial increase in the number of occupational diseases in two years. In conclusion, these clinics would help improving recognition of occupational diseases.

Keywords: Occupational diseases, occupational medicine specialty, notification of occupational diseases.

Received: 4 August 2020, Accepted: 22 March 2021

Published online: 7 June 2021

\section{INTRODUCTION}

Occupational diseases cause a significant public health burden [1]. Official reports and researches indicate that they are substantially underdiagnosed, globally [2]. Occupational medicine is a newly developing specialty in Turkey and the first duty of this specialty is to diagnose and notify occupational diseases. Turkey has a compensation-based occupational disease surveillance system which is run by Social Security Institution (SSI) [3]. Notifying occupational diseases is mandatory by law [4]. There are 2 dedicated occupational disease hospitals in Turkey, Ankara and Zonguldak. In addition to these hospitals, all state university hospitals and training and research hospitals are authorized for notifying occupational diseases to SSI [3]. Workplace physicians, family physicians, specialists in secondary care hospital are not allowed to notify to SSI directly, but they must refer the suspected occupational diseases to the authorized hospitals [3]. Despite the fact that, notification is mandatory, 
underreporting is very common. In a country with 80 million population and 30 million workers, the number of compensated cases by SSI in 2016 is 597 [5]. The reported number from hospitals is not officially announced, but it is estimated to be approximately 5000 per year. This number is a huge underestimate, according to the literature we should expect 4-12 occupational diseases per 1000 workers [6]. For 30 million workers the number should be between 120.000-360.000 per year. In their study, Kalayci et al. estimated approximately 500 thousand diseases should be related to work, in one year [7].

When the recording and notification system was established in Turkey, there were no residency trained occupational medicine specialists in the field. The system was conducted through experienced physicians and occupational disease hospitals. However, the first occupational medicine specialist is graduated in 2017 and in practice for 3 years. New occupational medicine specialists have graduated and approximately 40 residents are on the way.

In this study, we want to evaluate the two-year data of this first occupational medicine clinic ran by a residency-trained occupational medicine specialist. We will compare the data within Turkey, from previous year's data without such a dedicated clinic in order to understand if these clinics make a difference and improve notification. If there is an improvement, we can propose increasing the number of occupational medicine specialists and these dedicated clinics.

\section{MATERIALS and METHODS}

This is a descriptive study which was accomplished in 2019 by retrospective assessment of medical files of patients who applied to Occupational Outpatient Clinic Yunus Emre Hospital, Eskisehir, Turkey between June 2017 and Augustus 2019. The written administrative permissions were received before the study and the study was conducted in accordance with the Declaration of Helsinki.

All patients who were referred with suspicion of an occupational disease by workplace physicians, family physicians and specialists from secondary care health centers; the patients who applied by themselves; and the patients with a previous diagnosis of an occupational disease and applied for follow-up are included to the study. The patients who applied for fitness for work and periodic examinations are not included. Data were collected from medical files of hospital electronic database system. Demographic data, occupational history, diagnosis and some imaging findings are recorded.

\section{RESULTS}

In two years, a total of 493 patients were admitted to the occupational medicine outpatient clinic. 2 patients are excluded because of missing data. The study was conducted with 491 patients. The flow diagram of the study is given in figure 1 .

The study group was consisted of 437 (89\%) males and 54 females. The average age of the whole group was $42.14 \pm 8.97$. Approximately half of the patients were smoking and working duration was 11.6 years for the group. The demographic characteristics of the study group is given in table 1.

Workplace physicians referred 188 (38.2\%) of the patients. 176 of them were referred by specialists working in a hospital and 153 of these were pulmonary medicine specialists. The distribution of referral centers is given in table 2 .

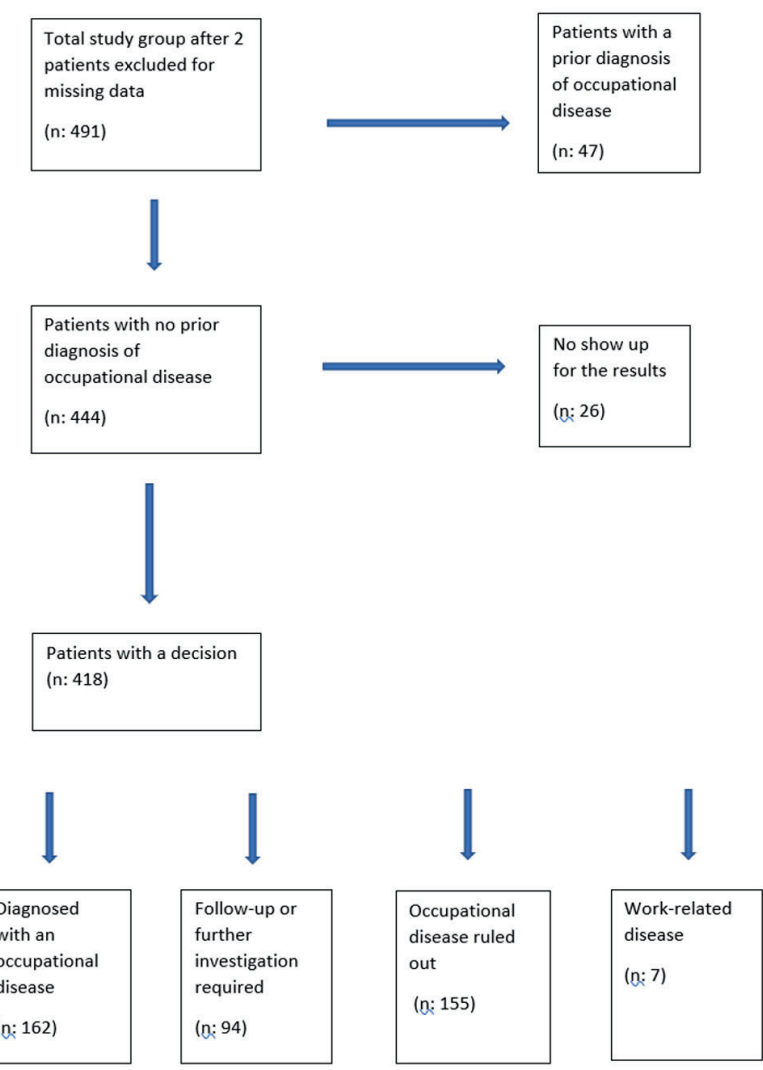

Figure 1. The flowchart of the study 
Table 1. Demographic characteristics of the patients

\begin{tabular}{|l|l|l|l|}
\hline & & All patients & Patients who received an occupational disease diagnosis \\
\hline Age & (years) & $42.1 \pm 8.9$ & $41.3 \pm 9.4$ \\
Gender & Male $\mathrm{n}(\%)$ & $437(89 \%)$ & $139(85.8 \%)$ \\
& Female $\mathrm{n}(\%)$ & $54(11 \%)$ & $23(14.2 \%)$ \\
Smoking cigarettes & $\mathrm{n}(\%)$ & $272(55.3 \%)$ & $92(56.7 \%)$ \\
Working duration & (years) & $11.6 \pm 8.38$ & $10.6 \pm 8.9$ \\
\hline Total & & $\mathbf{4 9 1 ( 1 0 0 )}$ & $\mathbf{1 6 2 ( 1 0 0 )}$ \\
\hline
\end{tabular}

Table 2. The distribution of centers referring patients to our clinic

\begin{tabular}{|l|c|c|}
\hline & All patients & Patients who received an occupational disease diagnosis \\
\hline The center & $\mathrm{n}(\%)$ & $\mathrm{n}(\%)$ \\
\hline Workplace physician & $188(38.2)$ & $41(25.3)$ \\
Specialist referral & $176(35.8)$ & $65(40.2)$ \\
Individual application & $110(22.4)$ & $54(33.3)$ \\
Disability medical board & $13(2.6)$ & $1(0.6)$ \\
Courtroom & $4(0.8)$ & $1(0.6)$ \\
\hline Total & $491(100)$ & $162(100)$ \\
\hline
\end{tabular}

In the study group, 47 patients had a prior diagnosis of an occupational disease. All of them were male and had pneumoconiosis. 32 (68\%) of them were working in ceramics industry.

444 patients had no history of occupational disease at the time of admission. 26 of them did not show up for the results assessment. Therefore, a decision was made for 418 patients. For 155 (37\%) of these patients, an occupational disease was ruled out. 94 patients were required a follow-up between 6-12 months. 7 patients were diagnosed with a workrelated disease.

162 patients (38.7\%) were diagnosed with an occupational disease. Of these patients 23 were female and 139 (85.8\%) were male. Average working time was $10.69 \pm 8.38$ years for this group. 92 of them were smoking and 15 of them quit smoking. $41(25 \%)$ of them were referred by workplace physicians and 65 of them were referred by specialists in the hospital. 52 patients were working in ceramics industry and 48 were from metal industry. The sectors in which the study group are working is given in table 3.

Of these patients, 72 were diagnosed with pneumoconiosis, 27 had heavy metal poisoning, 23 of them had musculoskeletal disease and 12 had occupational asthma. The diagnoses of this group are given in table 4 . For all these patients, a medical evaluation report was prepared and then they were referred to an authorized healthcare center for notification.

All patients were exposed to a mix of hazards. The main exposure was silica exposure (66.2\%). Welding fumes, heavy metals, and ergonomic hazards were other exposures.

According to the Eskisehir city Social Security Center there were 17 suspected cases referred to an occupational disease hospital in 2016 (a year before the occupational medicine clinic). Direct notification of an occupational disease from this city was 0 in 2016 [5].

\section{DISCUSSION}

We evaluated two-year data of the first occupational medicine clinic in a secondary care hospital, ran by the first residency-trained occupational medicine specialist, in Turkey. Local newspapers and official website of the hospital made public announcement of the clinic. However, total number of patients are relatively few when compared to occupational diseases hospitals. Many factors may contribute to this, but the most important factor is the hospital was unauthorized for notification of occupational disease which caused hesitation of workplace physicians to refer to this hospital. Other factors may include; reluctance of employees with the fear of losing their jobs, the employers' perception of 
Table 3. Distribution of patients according to the industry

\begin{tabular}{|l|c|c|}
\hline & All patients & Patients who received an occupational disease diagnosis \\
\hline Sector & $\mathrm{n}(\%)$ & $\mathrm{n}(\%)$ \\
\hline Ceramics industry (sanitaryware) & $177(36.0)$ & $33(32.7)$ \\
Metal industry & $65(13.2)$ & $10(6.1)$ \\
$\begin{array}{l}\text { Brick, tile, roof tile, porcelain, cement, marble } \\
\text { manufacturing }\end{array}$ & $53(10.7)$ & $21(12.9)$ \\
$\begin{array}{l}\text { Metal manufacturing (aviation, automotive, } \\
\text { railways, other) }\end{array}$ & $47(9.5)$ & $13(8.0)$ \\
$\begin{array}{l}\text { Service sectors } \\
\text { Mining }\end{array}$ & $42(8.5)$ & $5(3.0)$ \\
Glass manufacturing & $30(6.1)$ & $3(1.8$ \\
Other sectors & $18(3.6)$ & $20(12.3)$ \\
\hline Total & $59(12.0)$ & $162(100)$ \\
\hline
\end{tabular}

Table 4. Distribution of occupational disease diagnoses

\begin{tabular}{|l|c|}
\hline Diagnosis & $\mathrm{n}(\%)$ \\
\hline Pneumoconiosis & $80(49.3)$ \\
Heavy metal poisoning & $26(16.0)$ \\
Musculoskeletal disease & $23(14.1)$ \\
Occupational dermatoses & $13(8.0)$ \\
Occupational asthma & $10(6.1)$ \\
Noise induced hearing loss & $4(2.4)$ \\
Other & $6(3.7)$ \\
\hline Total & $162(100)$ \\
\hline
\end{tabular}

economic loss when declaring a workplace hazard and unawareness of physicians about occupational diseases [8].

The main advantage of this dedicated clinics was the relatively more time to obtain occupational history. This allowed the physician to diagnose many occupational diseases only by history taking. Many studies emphasized the importance of occupational history taking [9-11]. Another important advantage is that, this clinic, as being a local center, evaluated the workers in the city they lived. Our results show that for approximately $40 \%$ of the workers an occupational disease diagnosis was ruled out. This removed an unnecessary economic and psychological burden over the workers and the employer. The follow up examinations are also made in the same clinic.

Specialist referrals were coming mostly from pulmonary medicine specialists. This may be caused by the main sectors and diseases related to the exposures in those sectors are related to pulmonary medicine. But it may also be caused by the knowledge and awareness of pulmonary medicine specialists about occupational diseases. It is interesting that family medicine specialists referred very few patients, despite all the family physicians in Eskisehir received occupational medicine training and informed about the new occupational medicine clinic. This issue was discussed in many articles and they suggest further training in order to increase awareness of family physicians $[2,12,13]$.

The main sector where occupational diseases are mostly seen was ceramics industry. It is not clear if this is caused by that they are the most hazardous industry or their awareness is high and referring their patients? Pneumoconiosis in ceramics industry is vastly investigated in the literature [14, 15]. However, many studies show that occupational diseases are found if they are looked for. Acute pneumoconiosis in denim sandblasters was a good but unfortunate example for this [16]. Therefore, trainings should be provided to the employers and employees of other potential hazardous sectors in order to find out hidden occupational diseases in those sectors [17]. 
When the data of Social Security Institution is investigated, it is seen that there was not any notification of an occupational disease in 2016 [5]. There is an authorized center for notification of occupational diseases in the city (a university hospital), however, they did not make a notification. There is no dedicated occupational medicine clinic in that hospital.

\section{Limitations of The Study}

The study is an observational study; therefore, it does not allow us to make causal assumptions. Another limitation is that it compares the compensation data of SSI with the data of an outpatient clinic. However, there are no formal data other than SSI's compensated case numbers.

\section{CONCLUSION}

Our single center experience shows that dedicated outpatient occupational medicine clinics are very important for notification of occupational diseases. The 162 diagnosis in two-years, in the dedicated occupational clinic (despite the authorization problem) clearly shows that these clinics make a difference. These clinics also provide local solution for employers and employees which removes the economic burden of going to another city. These clinics should be in main cities countrywide and the infrastructure (such as manpower, laboratory support) should be empowered.

\section{CONFLICT Of INTEREST STATEMENT}

The authors declare that there is no conflict of interest.
[1] Fingerhut M, Nelson DI, Driscoll T, et al., The contribution of occupational risks to the global burden of disease: summary and next steps. Med Lav, 2006. 97(2): 313-321.

[2] Curti S, Sauni R, Spreeuwers D, et al., Interventions to increase the reporting of occupational diseases by physicians. Cochrane Database Syst Rev, 2015(3).

[3] Çalışma Gücü ve Meslekte Kazanma Gücü Kaybı Oranı Tespit Iş̧lemleri Yönetmeliği. 2008, T.C. Resmî Gazete.

[4] İş Sağlığı Ve Güvenliği Kanunu. 2012, T.C. Resmî Gazete.

[5] SGK Istatistik Yilliklari. 2016 [cited 2016 25.12.2016]; Available from: http://www.sgk.gov.tr/wps/portal/sgk/tr/ kurumsal/istatistik/sgk_istatistik_yilliklari.

[6] Aw TC, Gardiner K, Harrington JM. Pocket Consultant: Occupational Health 5ed. 2007, Oxford: Blackwell Publishing.

[7] Kalaycı D, Alagüney ME, Yıldız A. The Estimated Number of Occupational Diseases and Work-Related Diseases in Turkey. Acta Medica, 2019(50):17-24.

[8] Alaguney ME, Yildiz AN, Demir AU, et al., Physicians' opinions about the causes of underreporting of occupational diseases. Arch Environ Occup Health, 2020. 75(3):165-176.

[9] Binns C and Low WY. Lessons from Ramazzini for occupational health in the Asia-Pacific region. Asia Pac J Public Health, 2014. 26(6): 557-559.
[10] Lax MB, Grant WD, Manetti FA, et al., Recognizing occupational disease--taking an effective occupational history. Am Fam Physician, 1998. 58(4): 935-944.

[11] Alaguney ME, Yildiz AN. Taking an Occupational History and Its Importance. Acta Medica, 2017. 48(2): 20-23.

[12] Yildiz AN, Piskin TM, Alaguney ME, et al., Attitudes and behaviors of family physicians regarding occupational diseases. Arch Environ Occup Health, 2019. 74(1-2): 85-92.

[13] Elms J, O'Hara R, Pickvance S, et al., The perceptions of occupational health in primary care. Occup Med (Lond), 2005. 55(7): 523-527.

[14] Alici NS, Cimrin A, Coskun Beyan A. Pneumoconiosis in different sectors and their differences in Turkey. Tuberk Toraks, 2016. 64(4): 275-282.

[15] Karatas M, Guunduzoz M, Ozakinci OG, et al., Predictive risk factors for development of silicosis in Turkish ceramic workers. Tuberk Toraks, 2019. 67(1): 39-46.

[16] Akgun M. Denim production and silicosis. Curr Opin Pulm Med, 2016. 22(2): 165-169.

[17] ILO, The prevention of occupational diseases. 2013: Geneva. 